\title{
Aerosol-assisted Production of NIR Shielding Nanoparticles: Sodium Tungsten Bronze
}

\author{
Hao Tu, Weining Wang, Da-Ren Chen* \\ Department of Mechanical and Nuclear Engineering, Virginia Commonwealth University, Richmond, VA 23284, USA
}

\begin{abstract}
An aerosol-assisted process for continuously producing sodium tungsten bronze particles in one step was proposed. The effects of the precursor solution, solvent, heating temperature, and moisture concentration on the quality (i.e., crystallinity) of the products were systematically investigated. The mechanisms for the particle formation and the chemical reactions involved in this process were also studied. By varying the atomic ratio of sodium to tungsten in the precursor solution, sodium tungsten bronze particles in the cubic $\left(\mathrm{Na}_{0.70} \mathrm{WO}_{3}\right)$ and tetragonal $\left(\mathrm{Na}_{0.57} \mathrm{WO}_{3}\right)$ phases were monophasically produced. Particles in both phases showed near infrared (NIR) shielding properties. However, cubic-phase particles $\left(\mathrm{Na}_{0.70} \mathrm{WO}_{3}\right)$ possessed higher visibility in the visible light range due to their lower impurity content and higher crystallinity.
\end{abstract}

Keywords: NIR shielding particles; Sodium tungsten bronze crystal; Aerosol-assisted synthesis.

\section{INTRODUCTION}

Near infrared (NIR) light is the radiation that has the wavelength ranging from $0.75 \mu \mathrm{m}$ to $1.5 \mu \mathrm{m}$, which makes $\sim 18 \%$ solar radiation energy on the surface of the earth according to the previous measurement (ASTM International, 2012). The thermal effect of NIR increases the energy consumption for air conditioning (AC) of a building/ automobile in hot weather. In cold weather, keeping NIR from escaping to the outside can also reduce the loss of thermal energy by radiation. The energy uses for heating, ventilating and air conditioning (HVAC) of buildings is estimated at $\sim 50 \%$ of the total energy consumption for the building service in the U.S. and UK (Pérez-Lombard et al., 2008). The energy for HVAC operation of automobiles is $\sim 17 \%$ (Lambert and Jones, 2006). Shielding the NIR light through the windows of buildings and automobiles is thus in great demand for the energy-saving.

Various functional materials could be utilized to shield NIR from penetrating through transparent media such as glass. The commercial NIR shielding glass coating includes dielectric-Ag-dielectric films, metal-free solar reflecting films and functional particles-imbedded film (Padiyath et al., 2007). The dielectric-Ag-dielectric film reflects the NIR by the multiple-film structure of Ag layers and dielectric oxide layers, e.g., indium tin oxide (ITO) and antimony tin oxide (ATO) (Schaefer et al., 1997). Ag is applied in the layer

\footnotetext{
* Corresponding author.

E-mail address: dchen3@vcu.edu
}

because of its unique optical properties (Berning and Turner, 1957; Berning, 1983). Both ITO and Ag are expensive due to their production scale and storage (Padiyath et al., 2007). In addition, the manufacture of dielectric-Ag-dielectric films is by the sputtering processing, in which highly precise thickness control of the Ag layer is required, since the extra thickness of Ag layer would result in the dramatic reduction of visible light transmission (Padiyath et al., 2007). Furthermore, the presence of Ag layer could reduce the signal strength of cell phone, GPS etc. due to its high electrical conductivity. For the metal-free solar reflecting films, their NIR shielding function relies on the refractive index difference of polymer layers (Weber et al., 2000). The above films typically have laminated construction with hundreds of layers, and the commercial products of the above films have been applied on automobile since early 2000s (Padiyath et al., 2007). However, the irreversible aging of polymer-based films is typically occurred because of the $\mathrm{C}-\mathrm{C}$ bond is vulnerable to the high-energy UV photons in solar light. In general, the lifespan of a piece of high-quality metal-free solar reflecting film is $\sim 10$ years (Tintcenter.com, 2011). The above makes the metal-free films unpopular in the permanent cases such as architectural windows.

Without the requirement of any special film structure, the other candidates for the NIR shielding are the functionalparticle-imbedded films. Examples of these functional particles are rare-earth hexaboride $\left(\mathrm{ReB}_{6}, \mathrm{Re}=\mathrm{La}, \mathrm{Ce}, \mathrm{Pr}, \mathrm{Nd}\right.$ and $\mathrm{Gd})$ and tungsten bronze $\left(\mathrm{M}_{x} \mathrm{WO}_{3}, \mathrm{M}=\mathrm{Li}, \mathrm{Na}, \mathrm{Cs}, \mathrm{Ru}, \mathrm{K}\right.$, $\mathrm{NH}_{4}$ etc.) in the previous studies (Kimura et al., 1990; Takeda et al., 2008; Adachi et al., 2010; Guo et al., 2010, 2011, 2012a). The performance of rare-earth hexaboride particles is related with the particle size because the NIR 
absorption is based on the localized surface plasma resonance (LSPR) of conduction electrons (Takeda et al., 2008). Particles in a certain size range exhibits the effective NIR shielding. The range of wavelength for shielding NIR is also selective for the above particles (Kimura et al., 1990; Takeda et al., 2008). Different from the LSPR mechanism, tungsten bronze particles shield the NIR via the insertion of alkali ion into tungsten oxide crystal lattice to form a solid solution, which is commonly observed in either the cubic or tetragonal crystal phase. Due to the ternary addition of positive ions, free electrons are induced to interact with photons by dipole absorption, which is the reason for general wide-range NIR absorption by tungsten bronze (Svensson and Granqvist, 1984; Takeda and Adachi, 2007). Furthermore, as a family member of tungsten trioxide, tungsten bronze is insoluble in water and all acids except hydrofluoric acid (Luo, 2010). It implies that tungsten bronze is chemically stable in the indoor/outdoor environments.

The initial synthesis of tungsten bronze was reported by Wöhler (1824) via the thermal reduction of fused salts. Various tungsten bronzes $\left(\mathrm{M}_{x} \mathrm{WO}_{3}, \mathrm{M}=\mathrm{Li}, \mathrm{Na}, \mathrm{K}, \mathrm{Ru}, \mathrm{Cs}\right)$ were later produced by the thermal reduction method (Straumanis, 1949; Straumanis and Hsu, 1950; Magnéli and Blomberg, 1951). Combined with electrolysis, the highquality crystal (in millimeter sizes) of tungsten bronzes with the tuned $x$ in $\mathrm{M}_{x} \mathrm{WO}_{3}$ were produced (Brown and Banks, 1954; Shanks, 1972). The melt salt reaction generally requires to be in high temperatures and typically results in macrosized bulk products $(\sim 3 \mathrm{~cm})$. However, for the coating applications, micro- or nano-particles are more friendly to the processing (compared with macro-sized products). Grinding large crystals into the powder form is expensive in energy and easily contaminated. The wet chemical method has thus been used to first prepare the sol-gel precursor composed by amorphous tungsten oxide, and then to obtain the tungsten bronze powder through the thermal hydrogen reduction $\left(\mathrm{M}_{0.33} \mathrm{WO}_{3}, \mathrm{M}=\mathrm{Tl}, \mathrm{Rb}, \mathrm{Cs}\right)$ (Takeda and Adachi, 2007). By the time-consuming solvothermal reaction, nanoparticle of tungsten bronzes $\left(\mathrm{M}_{x} \mathrm{WO}_{3}, \mathrm{M}=\mathrm{K}, \mathrm{Ru}, \mathrm{Cs}, \mathrm{NH}_{4}\right)$ were directly synthesized at low temperature (Guo et al., 2010, 2011, $2012 \mathrm{a}, \mathrm{b})$. Although multiple methods were proposed to produce tungsten bronze particles, the worldwide production of tungsten bronze powders remains extremely low. It is because the processing methods including the melting salt, powder grinding, hydrothermal and calcination is energycostly and time-consuming.

Aerosol-based processing has been applied to produce particles in the sub-micrometer and even nanometer size range (Messing et al., 1993; Eerikainen et al., 2003). Because of its continuous operation at high rate (Charitidis et al., 2014) and the high reproducibility for the product quality and purity (Gurav et al., 1993), aerosol-based process is in general considered as a synthesis method easy for the future scale-up production. Furthermore, the characteristics of particles could be controlled in tube reactors by varying the tube temperature, flow rate and chemical composition of solutions in aerosol-based synthesis (Gurav et al., 1993). To make the synthesis of tungsten bronze easy for the future scale-up production, the flame-assisted method was proposed in the work of Hirano et al. (2018) for producing cesium tungsten bronze particles. In their report, the precursor can be continuously produced by flame-assisted synthesis. However, another individual annealing remains necessary to promote the crystallinity and eliminate the multiple phases. Furthermore, cesium is used as doping ion into the tungsten oxide in their work. Since the nature abundance of cesium is very low, the price of cesium compound is very high for large-scale producing of NIR shielding materials. So, in order to make the tungsten oxide bronze to be feasible for industry-scale producing for NIR shielding, a simple onestep method which can continuously produce crystallized and monophasic particles remains a challenge. The needs are also found in electrochromic and gas-sensing nanomaterial, which rely on the crystalline tungsten oxide compounds.

In this work, we used a droplet-based process to efficiently synthesize sodium tungsten bronze particles in crystalline and single phase. By varying the composition of precursor solutions, the effect of particle crystal phase on the optical property was investigated. The near-infrared absorption property of as-synthesized sodium tungsten bronze nanoparticles in cubic and tetragonal phases were evaluated.

\section{METHODS AND EXPERIMENTAL SETUP}

Fig. 1 shows the schematic diagram of the experimental setup for preparing sodium tungsten nanoparticles. The system utilized a custom-made Collison atomizer to generate the polydisperse droplets from the precursor solutions. Different from a typical Collison atomizer in which the spray solution is kept in the spray chamber, the spray solution $(\# 0)$ is fed to the spray nozzle of this atomizer from a syringe driven by a syringe pump (NE-1000; New Era Pump Systems). The compressed $\mathrm{N}_{2}$ gas was used as the spray and carry flow to operate the atomizer. The pumping rate was set at $300 \mu \mathrm{L} \mathrm{min}{ }^{-1}$. The pressure of nitrogen carry gas flow was set at 25 psi, resulting in the flow rate of $\sim 2 \mathrm{~L} \mathrm{~min}^{-1}$ (standard liters per minute).

The \#0 solution is the mixture of two solutions, A and B, in different percentages by volume. Solution A was prepared by dissolving the $7.93 \mathrm{~g}(0.02 \mathrm{~mol})$ of tungsten chloride ( $\mathrm{WCl}_{6}$; Acros Organics) and the $1.16 \mathrm{~g}(0.02 \mathrm{~mol})$ of sodium chloride ( $\mathrm{NaCl}$; Acros Organics) in $1000 \mathrm{~mL}$ methanol $\left(\mathrm{CH}_{3} \mathrm{OH}\right.$; Alfa Aesar). The above solution was sealed in a bottle for continuously stirring for 3 days (at the room temperature). Solution B was prepared in the same process as described without the addition of sodium chloride. All these solutions were kept sealed in glass bottles and stored in chemical closets at room temperature. The molar $\mathrm{Na} / \mathrm{W}$ ratio of the test $\# 0$ solution is summarized in Table 1 . The \#0 solution was transferred to a syringe for the experiments.

Prior to entering the high-temperature tube furnace, the produced droplet stream in the atomizer was mixed with two other nitrogen flows (\#1 and \#2) while keeping the total flow rate of \#1 and \#2 at $500 \mathrm{~cm}^{3} \mathrm{~min}^{-1}$ (standard cubic centimeters per minute). The \#2 nitrogen flow bubbled through DI water kept in a container to carry water vapor. The DI water container was kept at $55^{\circ} \mathrm{C}$. At the temperature, the moisture concentration in the \#2 flow is $0.23 \mathrm{~g} \mathrm{~L}^{-1}$. The moisture concentration was measured by weighing the water mass 


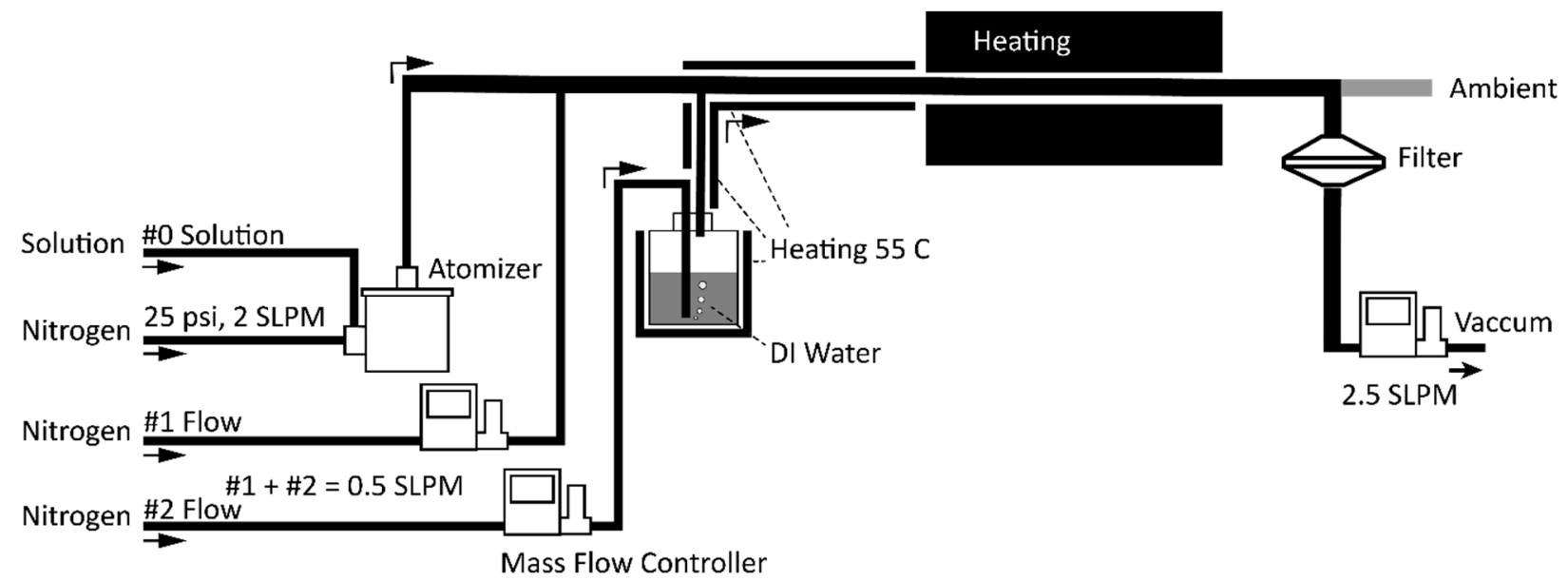

Fig. 1. Schematic diagram of the experimental setup for the production of sodium tungsten bronze nanoparticles.

Table 1. The summary of $\mathrm{Na} / \mathrm{W}$ ratio in the precursor solution (\#0 in Fig. 1) used in this study.

\begin{tabular}{lllllllll}
\hline $\mathrm{Na} / \mathrm{W}$ atomic ratio in \#0 solution & 1.0 & 0.8 & 0.6 & 0.5 & 0.4 & 0.3 & 0.2 & 0 \\
\hline Solution A (vol\%) & 100 & 80 & 60 & 50 & 40 & 30 & 20 & 0 \\
Solution B (vol\%) & 0 & 20 & 40 & 50 & 60 & 70 & 80 & 100 \\
\hline
\end{tabular}

loss in DI water container in a specific time (1 hour). We assumed that the amount of water loss contributes to the moisture concentration in the flow. The specific moisture concentration in the total flow under different \#1 and \#2 flow rates were given in Table 2 for the reference. All the nitrogen flow rates were controlled by the mass flow controllers (Alicat Scientific).

The mixed flow in the total rate of $2.5 \mathrm{~L} \mathrm{~min}^{-1}$ was then directed into a quartz tube placed in a high-temperature tube furnace (Lindberg 1200C; Thermo Scientific). The retention time for the particle stream in the furnace was estimated at $\sim 10 \mathrm{~s}$. The furnace setting temperature was varied from 350 to $800^{\circ} \mathrm{C}$. The as-produced particles were collected on a filter medium (glass fiber filter; Pall Corporation) placed in a filter holder installed at the exit of the tube furnace. The collection flow rate was set at $2.5 \mathrm{~L} \mathrm{~min}^{-1}$ via a critical orifice and a vacuum pump. An additional opening line was also included in the setup to ensure the inlet of filter holder was near the ambient pressure.

To characterize sample particles, the XRD patterns of the particles were measured by X'Pert PRO PANalytical. The images and EDX spectrum of the samples were taken by the Hitachi SU-70 FE-SEM. We placed a piece of glass slide at the exit of the reactor tube in parallel with the flow direction to collect as-produced particles for SEM imaging. The XPS spectrum was analyzed by the PHI VersaProbe III scanning XPS microprobe. The UV-Visible-NIR spectrum was measured by the M-2000 ellipsometer (J.A. Woollam). The particles are dispersed in collodion/IPA (5 wt\%) solution. The concentrations of particles are adjusted to maintain the transmittance at NIR range equal to each other. Then $5 \mathrm{~mL}$ solution is spread onto $2^{\prime \prime} \times 2^{\prime \prime}$ glass slide to form homogeneous film. The size distribution of particles was measured with the Scanning Mobility Particle Sizer (SMPS; Model 3080 and CPC Model 3775; TSI Inc.).
Note that, when using the above setup to produce sodium tungsten bronze particles, the $\# 0$ solutions in the $\mathrm{Na} / \mathrm{W}$ ratio of 1.0 to 0 were used. The \#2 flow rate was kept at $0.5 \mathrm{~L} \mathrm{~min}^{-1}$ in the above both cases.

\section{RESULT AND DISCUSSION}

\section{Particle Formation in the Proposed Synthesis}

To understand how sodium tungsten bronze particles were transformed from droplets produced by the spray, we measured the size distributions of particles before and after the high-temperature tube furnace. In addition to the precursor solutions (i.e., with the salt concentration of only $0.02 \mathrm{M}$ ), methanol only, serving as both solvent and reduction agent, was used in this part of investigation. Figs. 2(a) and 2(c) shows the size distribution of particles prior to entering the tube furnace when spraying the precursor solution and pure methanol, respectively. Compared to that shown in Fig. 2(c), the size distribution shown in Fig. 2(a) has much higher number concentration and larger peak particle size. The above comparison indicates that the solvent contribution on the produced particle samples is negligible.

Figs. 2(b) and 2(d) are the size distributions of particles measured by SMPS after the high-temperature tube furnace when spray the precursor solution and pure methanol, respectively. Once passing thorough the furnace, the peak and number concentration of the particle size distribution initially produced by spray the methanol only were significantly reduced (compared with that shown in Fig. 2(c)). However, the peak and shape of the particle size distribution initially produced by spraying the precursor solution (Fig. 2(b)) remained unchanged when compared with that in Fig. 2(a) (while the number concentration was significantly reduced). The particle loss due to the diffusion and thermophoretic effect could be the reasons for the significant reduction of 
Table 2. The concentration of moisture in the carry flow at different rates (tested in this study).

\begin{tabular}{lllllll}
\hline \#1 flow rate $\left(\mathrm{cm}^{3} \mathrm{~min}^{-1}\right)$ & 500 & 400 & 300 & 200 & 100 & 0 \\
\#2 flow rate $\left(\mathrm{cm}^{3} \mathrm{~min}^{-1}\right)$ & 0 & 100 & 200 & 300 & 400 & 500 \\
Moisture concen. in total flow $\left(0.01 \mathrm{~g} \mathrm{~L}^{-1}\right)$ & 0 & 0.92 & 1.84 & 2.76 & 3.68 & 4.60 \\
\hline
\end{tabular}
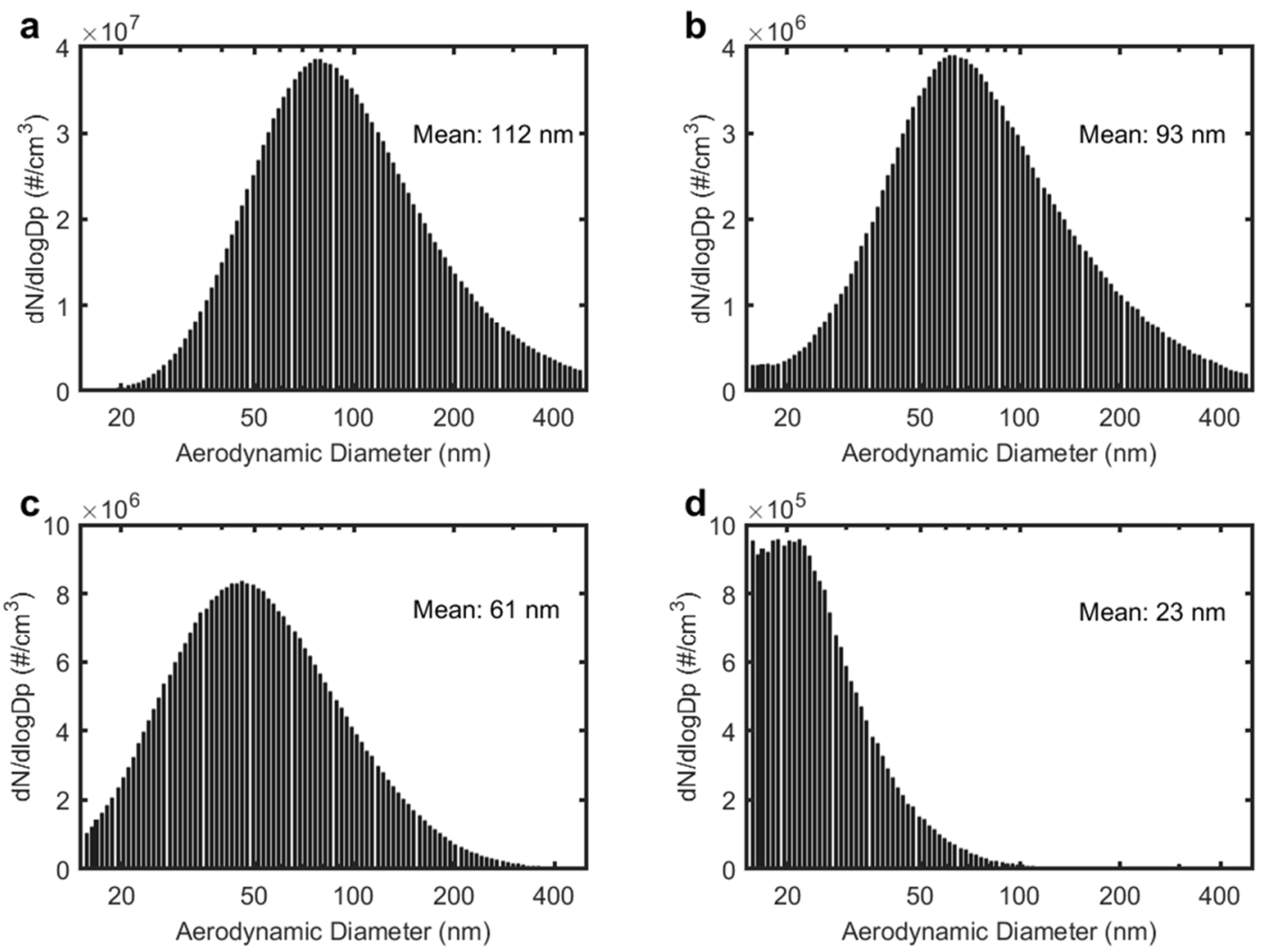

Fig. 2. Size distributions of particles, measured by SMPS: (a) at the entrance and (b) at the exit of tube furnace in the case of spraying the precursor solution (\#0); (c) at the entrance and (d) at the exit of tube furnace in the case of spraying the methanol only.

particle number concentration. The above observation implies the scenario of resultant crystal particle formation shown in Fig. 3 (i.e., one droplet was transformed into one resultant one and the liquid solvent was nearly vaporized prior to entering the tube furnace).

\section{Investigation of the Chemical Reaction in the Proposed Synthesis}

Fig. 4 shows the EDX data of sample products obtained under the various flow rates (\#2) passing through the DI water bottle. The series of EDX data evidences that the chlorine in the sample products increases from 0.28 to $5.46 \mathrm{wt} \%$ with the decrease of the moisture concentration (via the decrease of \#2 flow rate). Based on the above finding, the entire reaction in the tube reactor could be expressed in the following Eq. (1):

$$
\mathrm{WCl}_{6}+x \mathrm{NaCl}+\frac{x}{6} \mathrm{CH}_{3} \mathrm{OH}+\left(3+\frac{x}{6}\right) \mathrm{H}_{2} \mathrm{O} \rightarrow
$$

$\mathrm{Na}_{x} \mathrm{WO}_{3}+\frac{x}{6} \mathrm{CO}_{2}+(x+6) \mathrm{HCl}$
In Eq. (1), the $\mathrm{WCl}_{6}$ hydrolyzes with $\mathrm{H}_{2} \mathrm{O}$ to form tungsten oxide in the presence of $\mathrm{Na}^{+}$. Since the $\mathrm{Na}^{+}$atom is smaller than the void in $\mathrm{ReO}_{3}$ lattice of tungsten oxide, the sodium can easily diffuse into the lattice. According to the reaction, when there are not sufficient water molecules, the reaction would result in the additional chloride salt residue. As shown in Fig. 4, the chlorine weight percentage increases with the moisture flow rate (\#2 in Fig. 1) decreases. In addition, because the methanol is strongly reductive, it reduces the tungsten from VI valence to lower ones such as $\mathrm{V}$ or IV, which is similar to the hydrogen thermal reduction in other previous works (Hirano et al., 2018). The difference of our work compared with the previous ones is the use of methanol acting as the solvent and the reductant.

To evidence the reductive effect of methanol in the reaction, the flow rate of oxygen was added to mix with the particle flow prior to entering the tube furnace (Fig. 5). The introduction of oxygen will reduce the reductivity of the reacting flow, preventing the $\mathrm{W}(\mathrm{VI})$ from being reduced to the lower valence. Fig. 6 shows the XRD data of particle samples using the precursor solutions in different $\mathrm{Na} / \mathrm{W}$ ratios in the setups (Fig. 5). It is observed that the metal state 


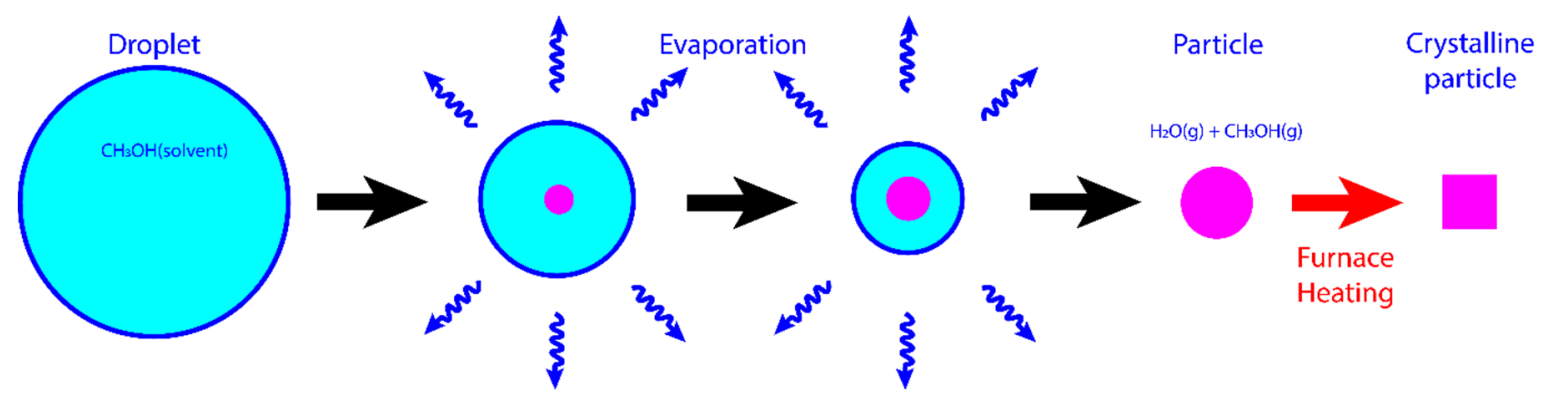

Fig. 3. The schematic diagram of crystal particle formation in this process.
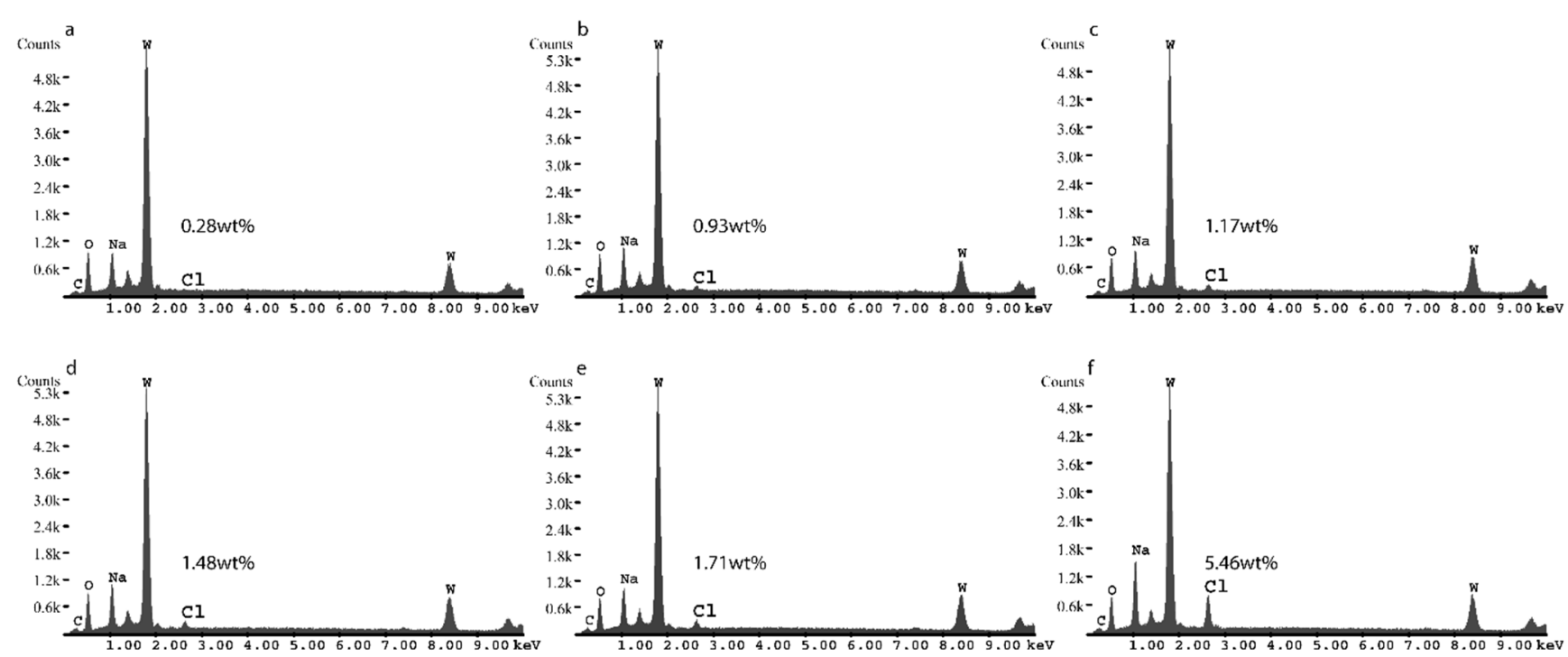

Fig. 4. EDX data of sample particle products obtained at the moisture flow rate (\#2 in Fig. 1) of (a) 500, (b) 400, (c) 300, (d) 200 , (e) 100 , and (f) $0.0 \mathrm{~cm}^{3} \mathrm{~min}^{-1}$. The tube furnace temperature is $800^{\circ} \mathrm{C}$. The $\mathrm{Na} / \mathrm{W}$ ratio is kept at 1.0 .

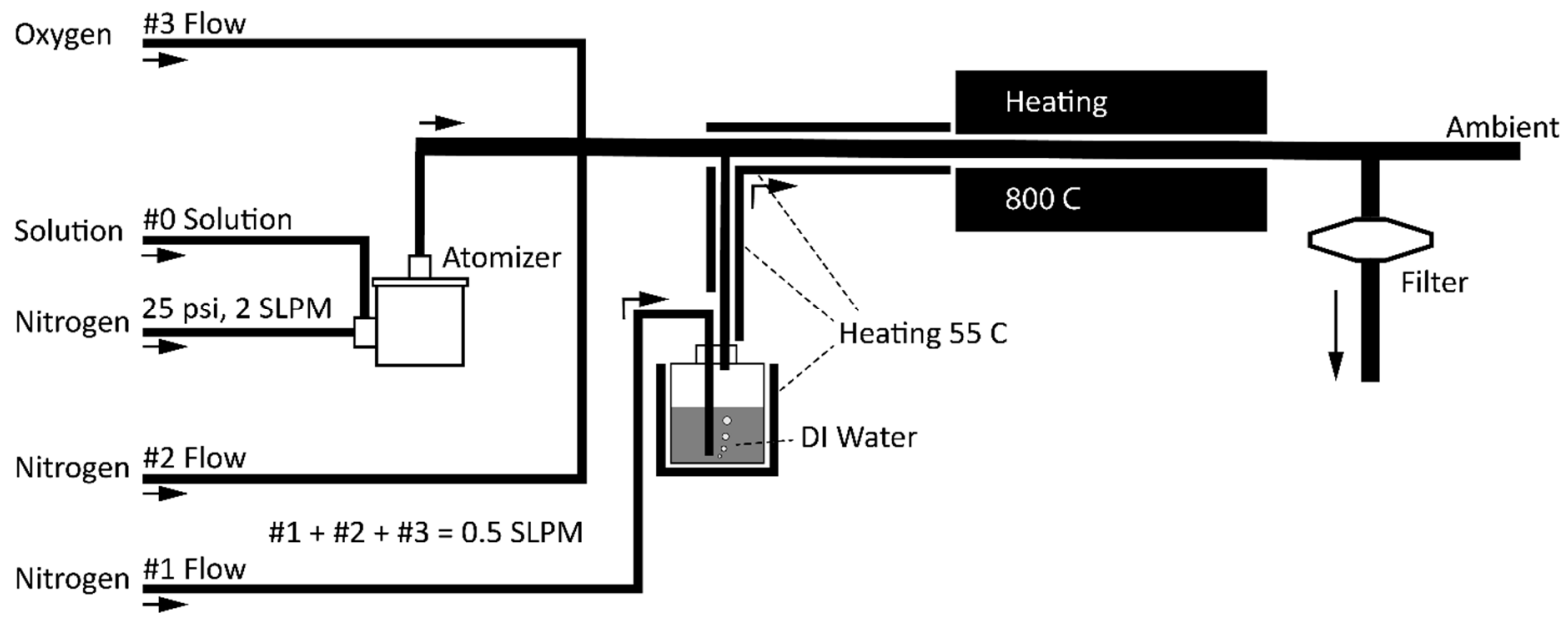

Fig. 5. The schematic diagram of the experimental setup for verifying the reductive role of methanol used in the process.

of tungsten always presents in the sample products obtained using precursor solutions of various $\mathrm{Na} / \mathrm{W}$ ratios when there is $\sim 8 \%$ oxygen in total flow rate, and no crystal structure in the products was observed when the oxygen percentage is above or below $8 \%$. The above finding indicates that the redox potential of methanol is not sufficient to reduce the $\mathrm{W}(\mathrm{VI})$ to the metal state $(0)$. Alternatively, the redox potential of intermediates might be capable. We hypothesize the intermediate is formaldehyde, whose redox potential is higher than methanol (Ferrin et al., 2008). Under a certain low concentration, the oxygen partially oxidizes methanol into formaldehyde. The W(VI) could thus be reduced to the metal state by the formaldehyde. It is concluded that methanol is a good candidate for serving as the solvent and 
a

$\mathrm{Na} / \mathrm{W}=1.0$

$-0.00-0.04-0.08-0.12-0.16$

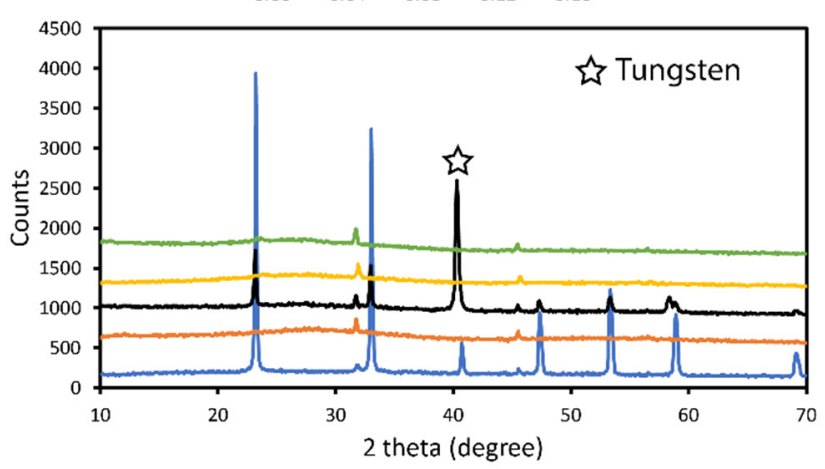

C

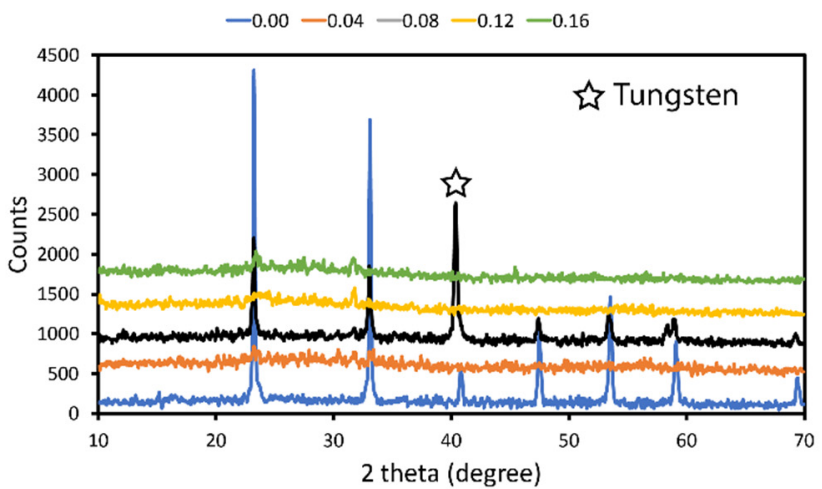

e
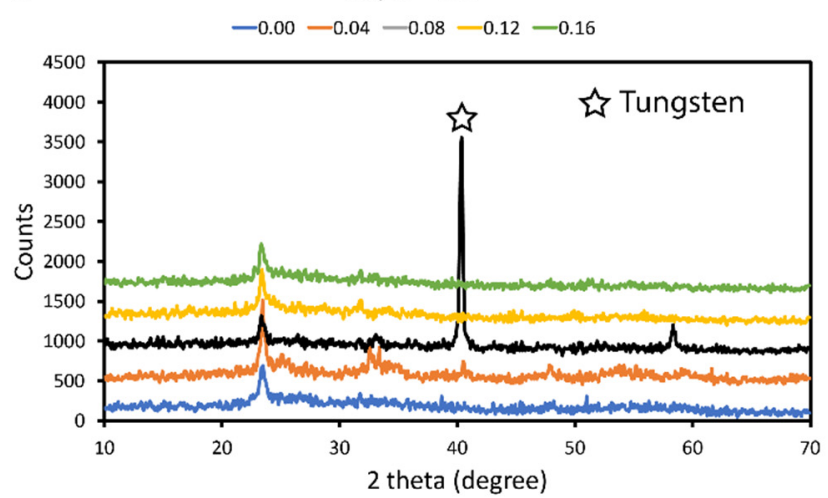

b

$\mathrm{Na} / \mathrm{W}=0.8$

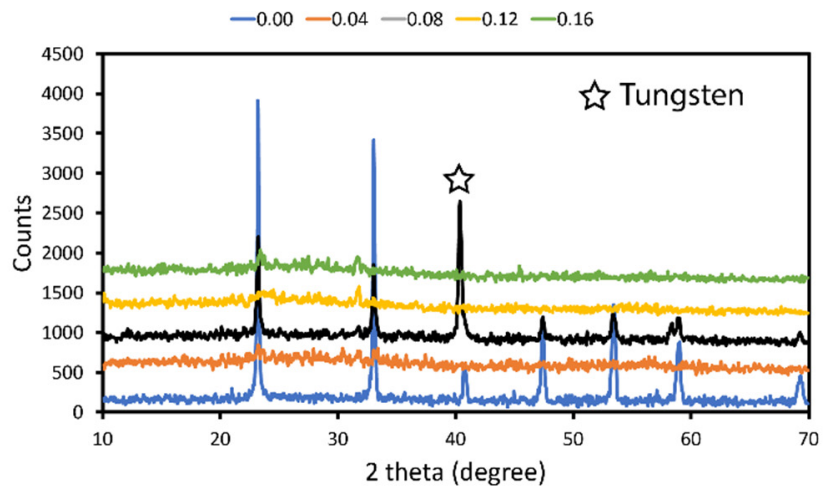

d

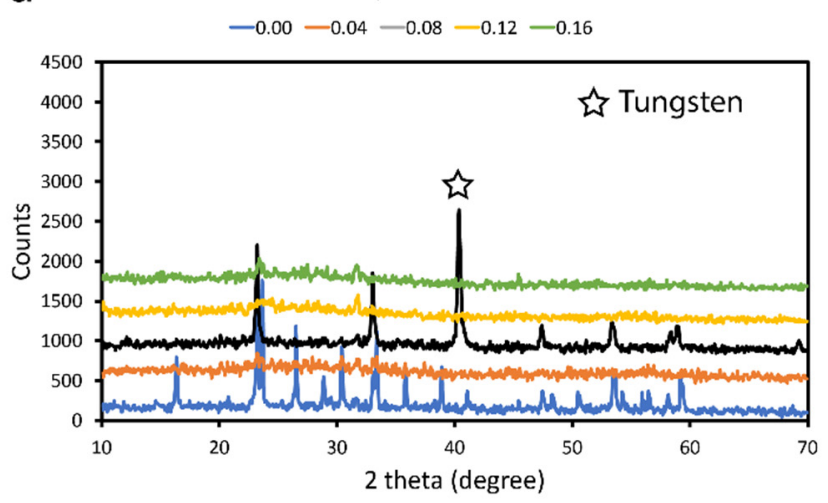

f

$\mathrm{Na} / \mathrm{W}=0$

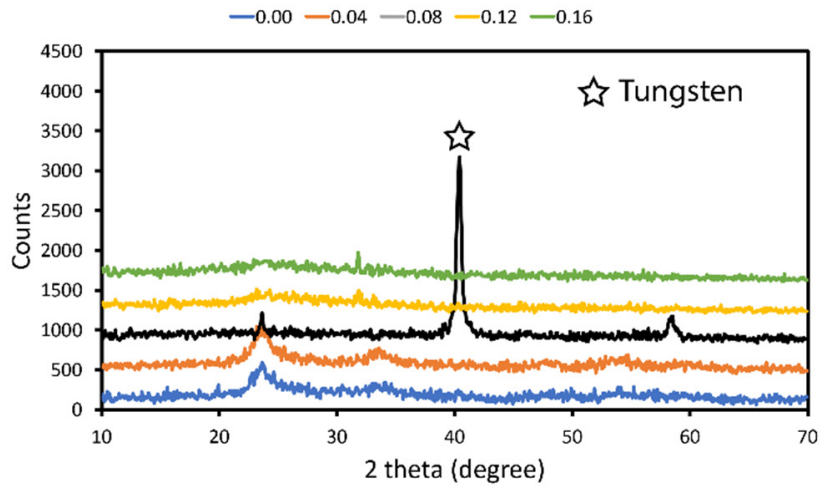

Fig. 6. Powder-XRD data of the particle products obtained when spraying the precursor solutions with the $\mathrm{Na} / \mathrm{W}$ ratio of (a) 1.00 , (b) 0.80 , (c) 0.60 , (d) 0.40 , (e) 0.20 and (f) 0.00 , and under the oxygen volume ratio in total flow was $0.00,0.04$, $0.08,0.12$ and 0.16 in different color lines.

reducing agent in the studied synthesis of sodium tungsten bronze because it is able to reduce the $\mathrm{W}(\mathrm{VI})$ to $\mathrm{W}(\mathrm{V})$ or W(IV) without the over-reduction.

\section{Effect of Precursor Solution and Furnace Temperature}

To study the effect of precursor solutions on the crystal phase and crystallinity of the products, the XRD data of powder samples obtained in the cases of spraying precursor solutions ( $\# 0$ in Fig. 1) in different $\mathrm{Na} / \mathrm{W}$ ratios were analyzed by the simulation. The sample products under the analysis were obtained at the furnace temperature of $800^{\circ} \mathrm{C}$, while the highest temperature inside furnace tube is $853^{\circ} \mathrm{C}$. Fig. 7 shows the comparison of the simulated and measured
XRD data of sample products. It is found that, with the decrease of the $\mathrm{Na} / \mathrm{W}$ ratio in the precursor solution, the percentage of the sample in the cubic phase is decreased and the percentage in the tetragonal phase is increased. Because of the sodium atom acting as the padding material inside the scaffold of $\mathrm{WO}_{3}$ for supporting the structure (i.e., with sodium atoms occupying the vacancy of $\mathrm{ReO}_{3}$ structure of $\mathrm{WO}_{3}$ ), the crystal lattice tends to form in the cubic phase. In contrary, with less sodium atoms, the crystal lattice of $\mathrm{WO}_{3}$ tends to collapse to form in the tetragonal phase. Note that, the pure $\mathrm{WO}_{3}$ could often forms in the tetragonal phase at the room temperature (Diehl et al., 1978). In specific, when the $\mathrm{Na} / \mathrm{W}$ ratio in the solution is larger than 0.8 , only the 

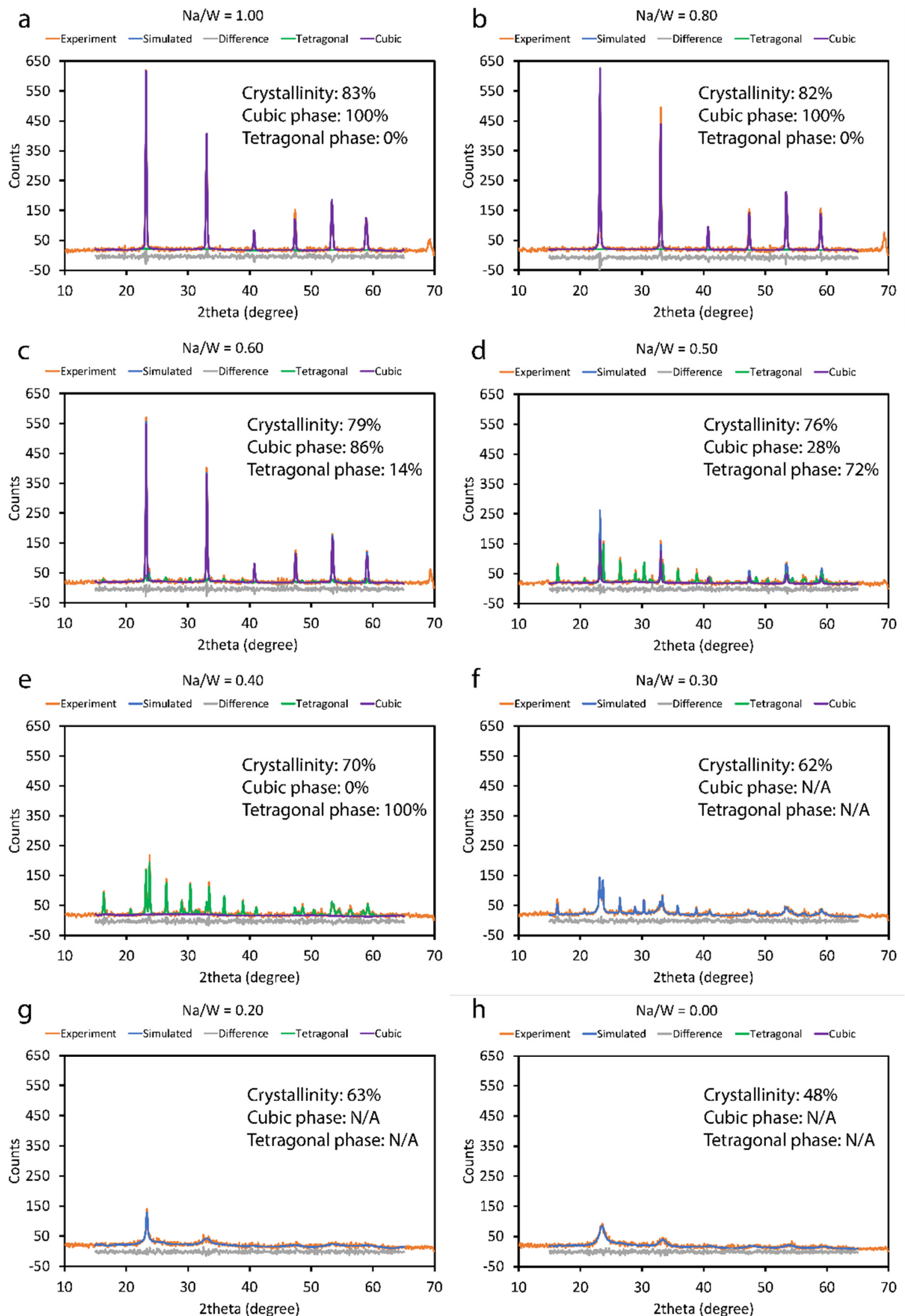

Fig. 7. Comparison of the experimental and simulated patterns of powder-XRD for the sample products obtained when spraying the precursor solutions with the $\mathrm{Na} / \mathrm{W}$ ratio of (a) 1.00 , (b) 0.80 , (c) 0.60 , (d) 0.50 , (e) 0.40 , (f) 0.30 , (g) 0.20 and (h) 0.00 . The samples in (a) and (e) are cubic phase and tetragonal phase, specifically. 
pure cubic phase was found in the sample products because the measured XRD patterns in Figs. 7(a) and 7(b) are well fit by the simulated ones in the cubic phase. On the other hand, when the $\mathrm{Na} / \mathrm{W}$ ratio is reduced to 0.40 , the sample powder is all in the tetragonal phase (Fig. 7(e)). As the Na/W ratio in the precursor solution further reduced, the crystallinity of products samples dramatically decreased and the phase composition analysis became not applicable (Figs. 7(f), 7(g) and 7(h)). The above observation is out of our expectation that crystalline tungsten oxide particles should be synthesized without the presence of sodium chloride. It suggests that the formation of crystalline $\mathrm{Na}_{x} \mathrm{WO}_{3}$ particles relies on the catalyzing by sodium ion. Since the melt point $\left(801^{\circ} \mathrm{C}\right)$ of sodium chloride is much lower than tungsten oxide $\left(1,473^{\circ} \mathrm{C}\right)$, the sodium chloride acts as the ceramic flux to facilitate tungsten atoms movement and lattice conversion via the liquefaction (Daly, 1996; Eppler and Obstler, 2005). Without the sodium chloride, the amorphous tungsten oxide product requires much time to form the crystal at the same $800^{\circ} \mathrm{C}$ (Takeda and Adachi, 2007).

Fig. 8 shows the powder-XRD of sample products obtained at the different furnace temperature setting from 400 to $600^{\circ} \mathrm{C}$ (with the measured highest temperature in the tube). It is found that the furnace temperature should be set above $450^{\circ} \mathrm{C}$ to promote the formation of the crystal of sodium tungsten bronze. As the furnace temperature was increased, the crystallinity of the product samples was increased.
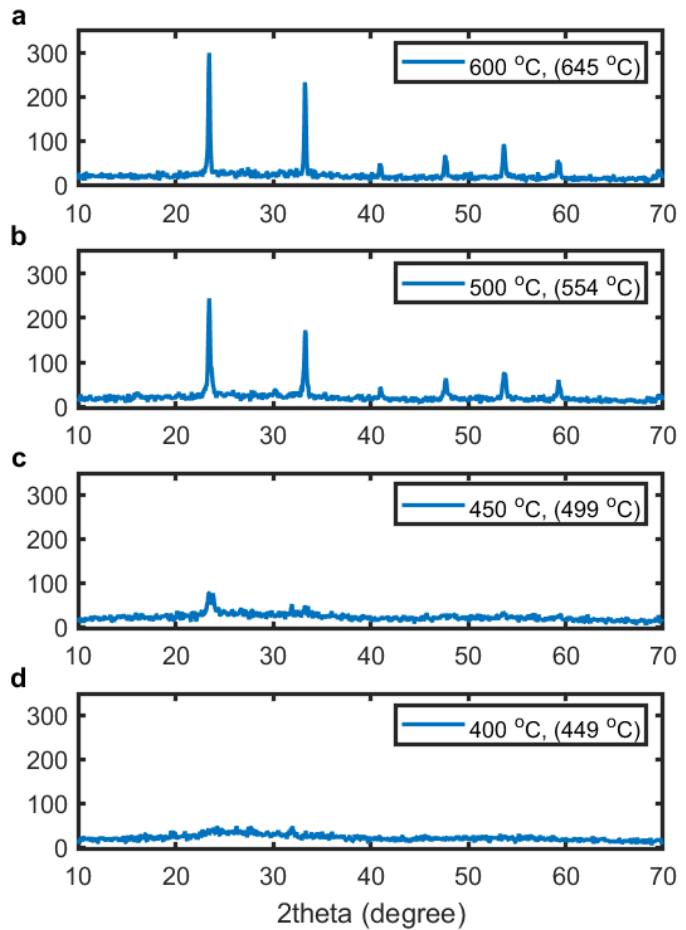

Fig. 8. Powder-XRD data of sample products obtained when the tube furnace was set at the temperature of (a) 600 , (b) 500 , (c) 450 , and (d) $400^{\circ} \mathrm{C}$ (the highest tube temperature is given in bracket). The samples were produced at $\mathrm{Na} / \mathrm{W}$ ratio of 1.0 and $\# 2$ flow rate of $0.5 \mathrm{~L} \mathrm{~min}^{-1}$ (standard liters per minute). \#1 flow rate is zero. The moisture mass concentration in total flow is $0.046 \mathrm{~g} \mathrm{~L}^{-1}$.

\section{Comparison of Sodium Tungsten Bronze Products in Phases}

To investigate sodium tungsten bronze particles in two phases, the micro morphologies of sodium tungsten bronze in the cubic and tetragonal phases are shown in Figs. 9(a) and 9(b), respectively. The cubic shape (Fig. 9(a)) and the orthogonal bar shape (Fig. 9(b)) of sample particles match well with the crystal lattice types of two typical samples. From the powder-XRD patterns in Figs. 9(c) and 9(d), it is found that all the peaks of the samples in both the cubic and tetragonal phases correspond very well with the reference positions of ICDD PDF 01-075-0232 and 01-070-0122. The sharp peaks indicate the excellent crystallinity of the samples. The cubic-phase sodium tungsten bronze has much high intensity of the peaks above the background, which is the evidence of better crystallinity than the tetragonal-phase bronze. Moreover, the calculated crystallinity of cubic and tetragonal phase of sodium tungsten bronze in Figs. 7(a) and 7 (e) are $83 \%$ and $70 \%$, respectively.

From the EDX data shown in Fig. 10, the $\mathrm{Na}: \mathrm{W}: \mathrm{Cl}$ ratio of the sample in the cubic phase is $\sim 0.72: 1.00: 0.02$ and 0.88:1.00:0.31 for the sample in the tetragonal phase. Assuming all chlorine atoms come from $\mathrm{NaCl}$, the $\mathrm{Na}: \mathrm{W}$ ratio in the sodium tungsten bronze crystal of the cubic phase were 0.70:1.00, and 0.57:1.00 for the sample in the tetragonal phase. The molecular formulas for the cubic and tetragonal tungsten bronze are thus $\mathrm{Na}_{0.70} \mathrm{WO}_{3}$ and $\mathrm{Na}_{0.57} \mathrm{WO}_{3}$, respectively.

By comparing the lattice size of cubic-phase sodium tungsten bronze in ICDD database (Fig. S1 in ESI), a linear equation between lattice size and $\mathrm{Na} / \mathrm{W}$ can be obtained. By submit the experimental value of cell size, 3.84 (from XRD) into the equation, the $\mathrm{Na} / \mathrm{W}$ ratio can be calculated out as 0.732 , which is very near to the value of $0.70\left(\mathrm{Na}_{0.70} \mathrm{WO}_{3}\right)$. Figs. 10(c) and 10(d) are the photos of cubic- and tetragonalphase sodium tungsten bronze samples, respectively. The purple-red color of cubic-phase sample and the blue color of tetragonal-phase sample are in line with the summary of color vs. ion content by Granqvist (1995). The color difference of two sample is the consequence of different tungsten chemical status. Because of more sodium atoms occupying the lattice void, the average tungsten valence in the cubicphase sample is lower than the tetragonal-phase one (Guo et al., 2012c), which should be verified by the XPS in Fig. 11.

The XPS data for the sample products in the cubic and tetragonal phases is shown in Fig. 11 (without and with the sputtering). For the surface tungsten atom, the $\mathrm{V}$ valence tungsten was observed in the cubic-phase sample (Fig. 11(a)) while no such peak area is identified in the sample of tetragonal phase (Fig. 11(c)). After the sputtering, the XPS data of cubic-phase sample (Fig. 11(b)) shows larger area of $\mathrm{V}$ or IV valence tungsten than the tetragonal-phase one (Fig. 11(d)). The above evidences that the tungsten in the cubic-phase sample has more reductive status than the tetragonal-phase one, which is the cause for the different band structure for the light absorption in the visible range.

Fig. 12 shows the transmittance of sample particles in the cubic and tetragonal phases. It is found that the cubic-phase sodium tungsten bronze particles show better transmittance 


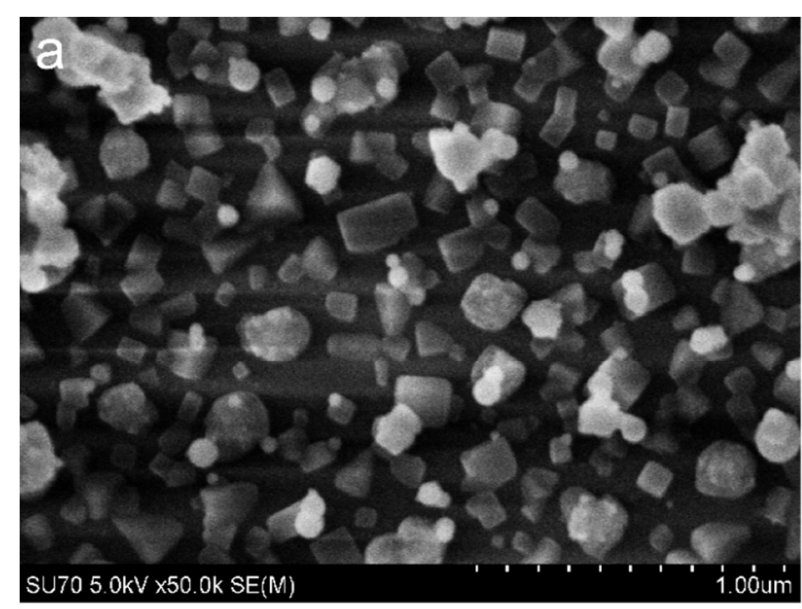

C

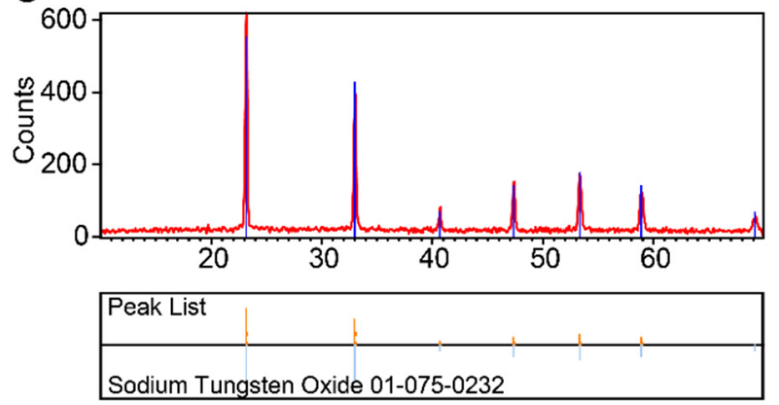

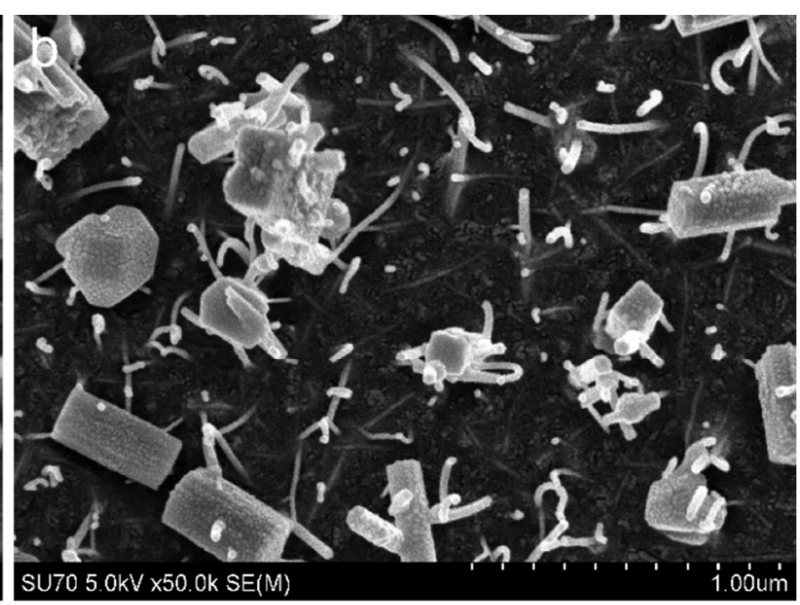

d
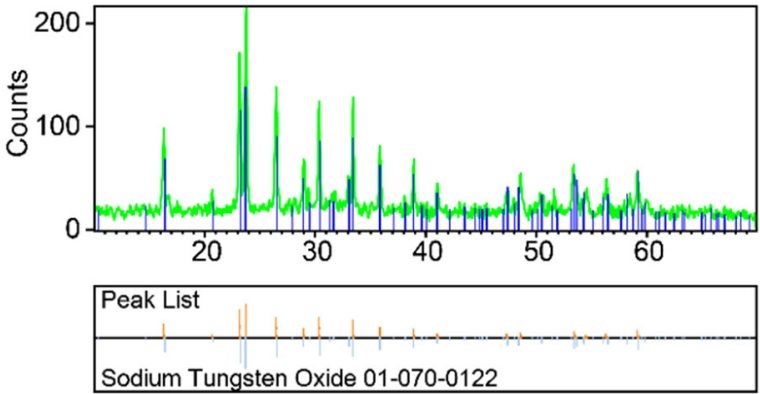

Fig. 9. SEM images and XRD data of sodium tungsten bronze particle samples in the (a, c) cubic phase and (b, d) tetragonal phase, respectively.

a

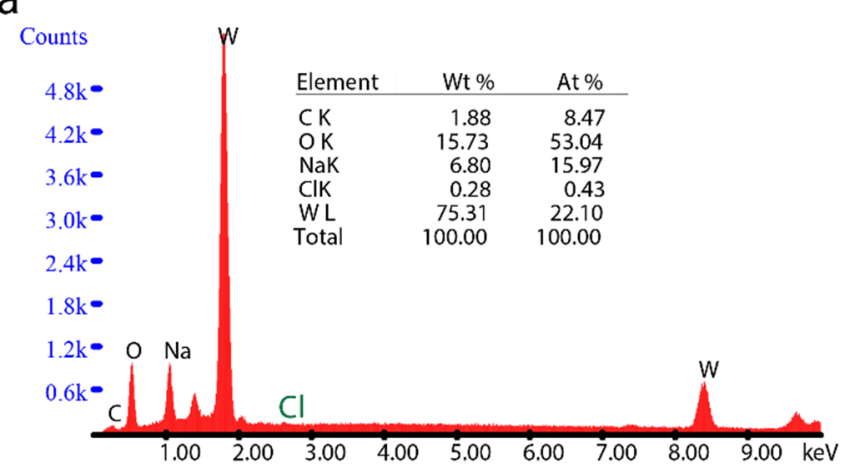

C

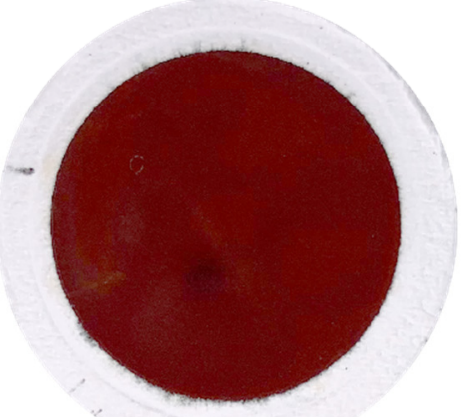

b

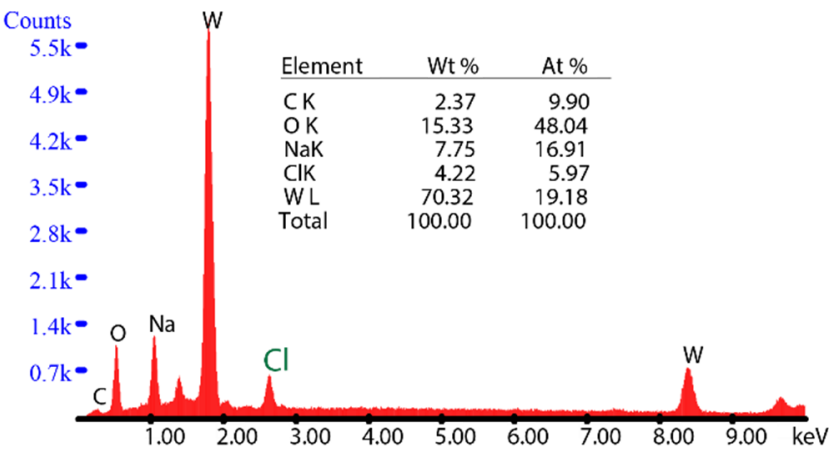

d

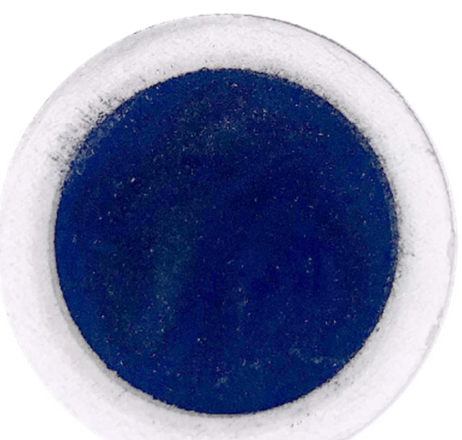

Fig. 10. EDX data of sodium tungsten bronze for (a) cubic phase and (b) tetragonal phase. Photos of sodium tungsten bronze particles in the (c) cubic phase and (d) tetragonal phase when collected on the filter medium. 

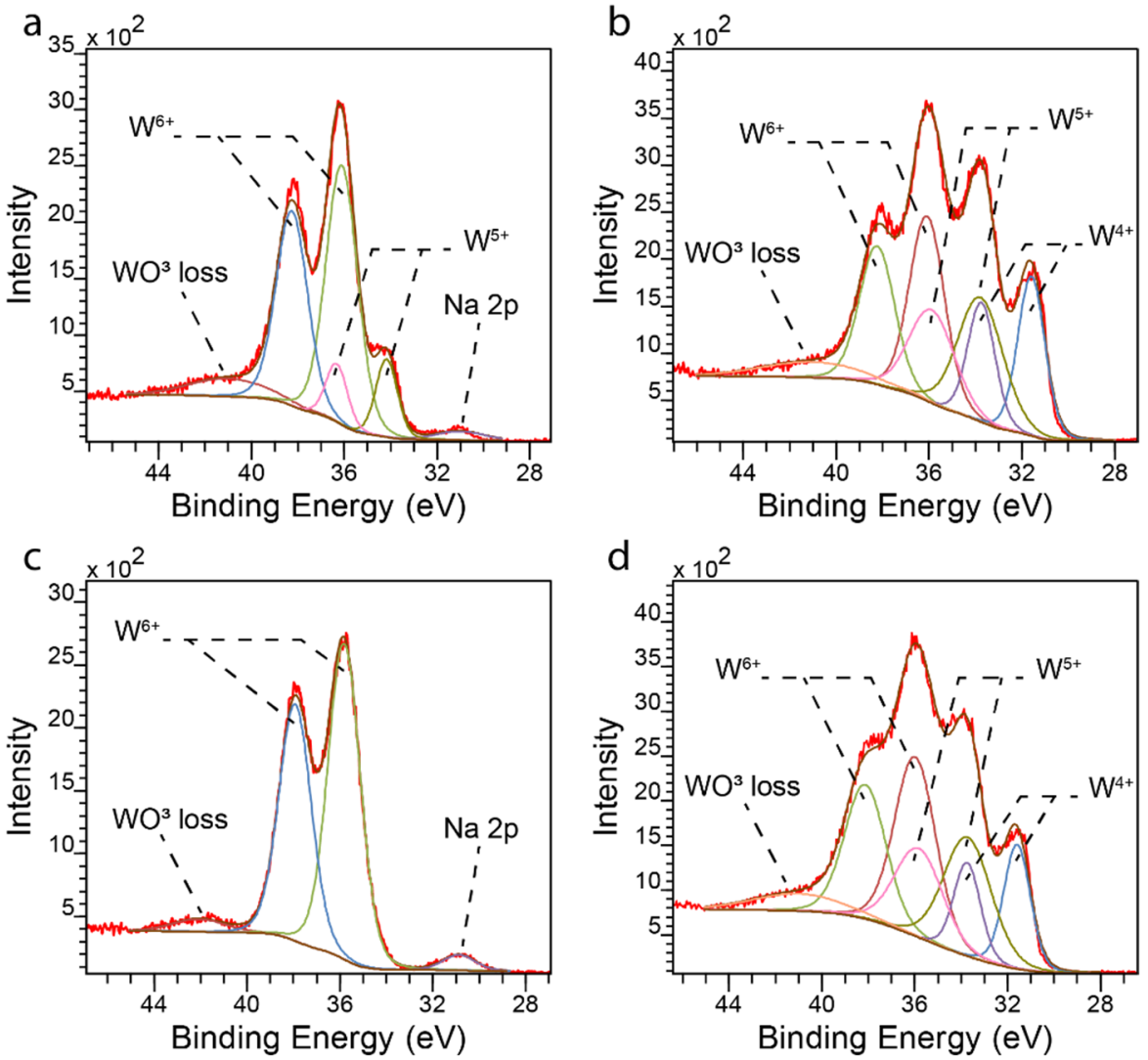

Fig. 11. XPS data of sodium tungsten bronze samples in the $(a, b)$ cubic and $(c, d)$ tetragonal phases without the sputtering and with the sputtering of $4 \mathrm{~min}$.

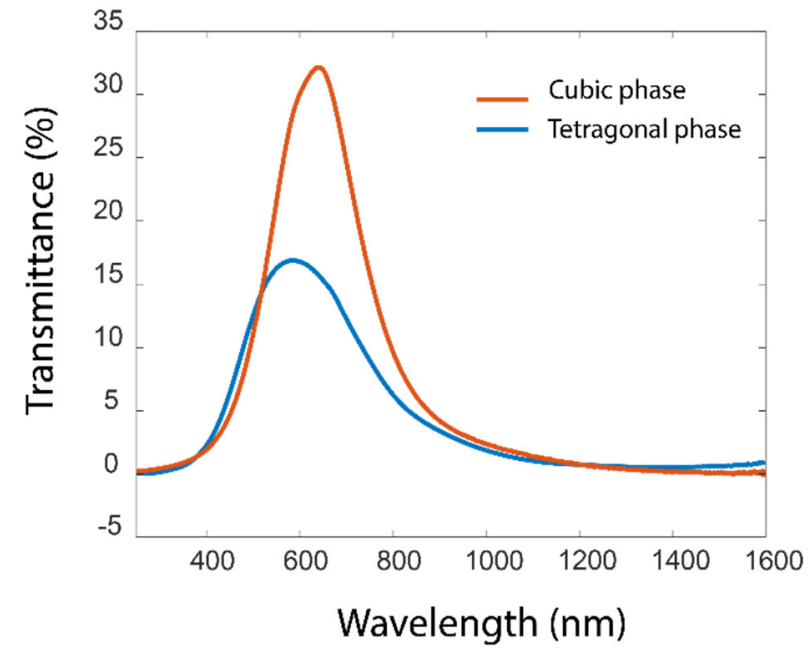

Fig. 12. Transmittance of the sample sodium tungsten bronze products in the cubic and tetragonal phases (as the function of wavelength). The mass concentration of particle in the medium are kept the same.

in the visible light range than the tetragonal-phase one. One possible reason for the observation is that the high content of sodium ion in the cubic-phase sample makes it highly efficient in the dipole absorption of NIR. Another possible reason is that the impurity content, carbon and chlorine, in the cubic-phase sample (8.47 and 0.43 at\%; Fig. 10(a)) are lower than the tetragonal-phase one (9.90 and 5.97 at\%; Fig. 10(b)). The other reason might be due to that the cubic-phase sample has the higher crystallinity, i.e., having less crystal boundary, compared with that of tetragonal-phase sample. The crystal boundary scatters the light, resulting in the reduction of transmittance.

\section{CONCLUSION}

A droplet-based synthesis process was developed to produce sodium tungsten bronze particles continuously in one step. This process consisted of atomizing the precursor solution into droplets, which were then carried by an $\mathrm{N}_{2}$ flow and mixed with a second, partially saturated $\mathrm{N}_{2}$ flow prior to entering a high-temperature tube furnace. Samples were subsequently collected at the exit of the furnace via filtration. Measuring the particle size distributions before and after the furnace heating stage, we found that each droplet served as a micro-reactor and produced one sodium tungsten bronze particle. We observed that the crystallinity was strongly related to the composition of the precursor solution-specifically, increasing the sodium content in the latter enhanced the former. This trend applied even as the furnace temperature was raised. Furthermore, given sufficient moisture content, the reaction resulted in only trace amounts of by-products $(\mathrm{NaCl})$.

Exploring the involved particle formation mechanisms and chemical reactions in greater detail, we also discovered 
the nearly complete evaporation of the methanol solvent from the individual droplets prior to their entry into the tube furnace. The resultant methanol vapor acted as a reductive regent in the reaction that occurred within each particle to facilitate crystallization.

By varying the $\mathrm{Na} / \mathrm{W}$ ratio in the precursor solution, highpurity sodium tungsten bronze particles in the cubic phase $\left(\mathrm{Na}_{0.70} \mathrm{WO}_{3}\right)$ and the tetragonal phase $\left(\mathrm{Na}_{0.57} \mathrm{WO}_{3}\right)$ were produced. Particles in both phases demonstrated NIR shielding abilities.

\section{SUPPLEMENTARY MATERIAL}

Supplementary data associated with this article can be found in the online version at http://www.aaqr.org.

\section{REFERENCES}

Adachi, K., Miratsu, M. and Asahi, T. (2010). Absorption and scattering of near-infrared light by dispersed lanthanum hexaboride nanoparticles for solar control filters. $J$. Mater. Res. 25: 510-521.

ASTM International (2012). ASTM G173-03(2012). Standard Tables for Reference Solar Spectral Irradiances: Direct Normal and Hemispherical on $37^{\circ}$ Tilted Surface, ASTM International, West Conshohocken, PA.

Berning, P.H. and Turner, A. (1957). Induced transmission in absorbing films applied to band pass filter design. $J$. Opt. Soc. Am. 47: 230-239.

Berning, P.H. (1983). Principles of design of architectural coatings. Appl. Opt. 22: 4127-4141.

Brown, B. and Banks, E. (1954). The sodium tungsten bronzes1, 2. J. Am. Chem. Soc. 76: 963-966.

Charitidis, C.A., Georgiou, P., Koklioti, M.A., Trompeta, A.F. and Markakis, V. (2014). Manufacturing nanomaterials: From research to industry. Manufacturing Review 1: 11.

Daly, G. (1996). Glazes and glazing techniques: A glaze journey. Gentle Breeze Pub.

Diehl, R., Brandt, G. and Salje, E. (1978). The crystal structure of triclinic $\mathrm{WO}_{3}$. Acta Crystallogr., Sect. B 34: 1105-1111.

Eerikainen, H., Watanabe, W., Kauppinen, E.I. and Ahonen, P.P. (2003). Aerosol flow reactor method for synthesis of drug nanoparticles. Eur. J. Pharm. Biopharm. 55: 357-360.

Eppler, R.A. and Obstler, M. (2005). Understanding Glazes. American ceramic Society, Westerville, Ohio.

Ferrin, P., Nilekar, A.U., Greeley, J., Mavrikakis, M. and Rossmeisl, J. (2008). Reactivity descriptors for direct methanol fuel cell anode catalysts. Surf. Sci. 602: 3424 3431.

Granqvist, C.G. (1995). Handbook of Inorganic Electrochromic Materials, Elsevier, Amsterdam.

Guo, C.S., Yin, S., Zhang, P.L., Yan, M., Adachi, K., Chonan, T. and Sato, T. (2010). Novel synthesis of homogenous $\mathrm{Cs}_{\mathrm{x}} \mathrm{WO}_{3}$ nanorods with excellent nir shielding properties by a water controlled-release solvothermal process. J. Mater. Chem. 20: 8227-8229.

Guo, C., Yin, S., Huang, L. and Sato, T. (2011). Synthesis of one-dimensional potassium tungsten bronze with excellent near-infrared absorption property. ACS Appl. Mater. Interfaces 3: 2794-2799.

Guo, C., Yin, S., Dong, Q. and Sato, T. (2012a). Simple route to $\left(\mathrm{NH}_{4}\right)_{\mathrm{x}} \mathrm{WO}_{3}$ nanorods for near infrared absorption. Nanoscale 4: 3394-3398.

Guo, C.S., Yin, S., Dong, Q. and Sato, T. (2012b). Nearinfrared absorption properties of $\mathrm{Rb}_{\mathrm{x}} \mathrm{WO}_{3}$ nanoparticles. Crystengcomm 14: 7727-7732.

Guo, C.S., Yin, S., Yan, M., Kobayashi, M., Kakihana, M. and Sato, T. (2012c). Morphology-controlled synthesis of $\mathrm{W}_{18} \mathrm{O}_{49}$ nanostructures and their near-infrared absorption properties. Inorg. Chem. 51: 4763-4771.

Gurav, A., Kodas, T., Pluym, T. and Xiong, Y. (1993). Aerosol processing of materials. Aerosol Sci. Technol. 19: 411-452.

Hirano, T., Nakakura, S., Rinaldi, F.G., Tanabe, E., Wang, W.N. and Ogi, T. (2018). Synthesis of highly crystalline hexagonal cesium tungsten bronze nanoparticles by flame-assisted spray pyrolysis. Adv. Powder Technol. 29: 2512-2520.

Kimura, S., Nanba, T., Kunii, S., Suzuki, T. and Kasuya, T. (1990). Anomalous infrared absorption in rare-earth hexaborides. Solid State Commun. 75: 717-720.

Lambert, M. and Jones, B. (2006). Automotive adsorption air conditioner powered by exhaust heat. Part 1: Conceptual and embodiment design. Proc. Inst. Mech. Eng. Part D 220: 959-972.

Luo, Y. (2010). CRC Handbook of Chemistry and Physics. CRC Press, Boca Raton.

Magnéli, A. and Blomberg, B. (1951). Contribution to the knowledge of the alkali tungsten bronzes. Acta Chem. Scand. 5: 372-378.

Messing, G.L., Zhang, S.C. and Jayanthi, G.V. (1993). Ceramic powder synthesis by spray-pyrolysis. J. Am. Ceram. Soc. 76: 2707-2726.

Tintcenter.com (2011). How long does auto tinting last? http://www.tintcenter.com/articles/bt_durability.html, Last Access: 19 March 2020.

Padiyath, R., Haak, C. and Gilbert, L. (2007). Spectrally selective window films. $50^{\text {th }}$ Annual Technical Conference of the Society of Vacuum Coaters, Louisville, Kentycky, USA, 2007, pp. 669-673.

Pérez-Lombard, L., Ortiz, J. and Pout, C. (2008). A review on buildings energy consumption information. Energy Build. 40: 394-398.

Schaefer, C., Bräuer, G. and Szczyrbowski, J. (1997). Low emissivity coatings on architectural glass. Surf. Coat. Technol. 93: 37-45.

Shanks, H.R. (1972). Growth of tungsten bronze crystals by fused salt electrolysis. J. Cryst. Growth 13: 433-437.

Straumanis, M. (1949). The sodium tungsten bronzes. I. Chemical properties and structure. J. Am. Chem. Soc. 71: 679-683.

Straumanis, M. and Hsu, S. (1950). The lithium tungsten bronzes1. J. Am. Chem. Soc. 72: 4027-4030.

Svensson, J. and Granqvist, C. (1984). Modulated transmittance and reflectance in crystalline electrochromic $\mathrm{WO}_{3}$ films: Theoretical limits. Appl. Phys. Lett. 45: 828830 . 
Takeda, H. and Adachi, K. (2007). Near infrared absorption of tungsten oxide nanoparticle dispersions. J. Am. Ceram. Soc. 90: 4059-4061.

Takeda, H., Kuno, H. and Adachi, K. (2008). Solar control dispersions and coatings with rare-earth hexaboride nanoparticles. J. Am. Ceram. Soc. 91: 2897-2902.

Weber, M.F., Stover, C.A., Gilbert, L.R., Nevitt, T.J. and Ouderkirk, A.J. (2000). Giant birefringent optics in multilayer polymer mirrors. Science 287: 2451-2456.

Wöhler, F. (1824). Über das wolfram. Ann. Phys. 78: 345358.

Received for review, October 30, 2019

Revised, February 17, 2020

Accepted, February 23, 2020 